Research Article

Bhuva Narayan*, Edward J. Luca, Belinda Tiffen, Ashley England, Mal Booth, Henry Boateng

\title{
Scholarly Communication Practices in
} Humanities and Social Sciences: A Study of Researchers' Attitudes and Awareness of Open Access

https://doi.org/10.1515/opis-2018-0013

Received February 16, 2018; accepted November 1, 2018

\begin{abstract}
This paper examines issues relating to the perceptions and adoption of open access (OA) and institutional repositories. Using a survey research design, we collected data from academics and other researchers in the humanities, arts and social sciences (HASS) at a university in Australia. We looked at factors influencing choice of publishers and journal outlets, as well as the use of social media and nontraditional channels for scholarly communication. We used an online questionnaire to collect data and used descriptive statistics to analyse the data. Our findings suggest that researchers are highly influenced by traditional measures of quality, such as journal impact factor, and are less concerned with making their work more findable and promoting it through social media. This highlights a disconnect between researchers' desired outcomes and the efforts that they put in toward the same. Our findings also suggest that institutional policies have the potential to increase OA awareness and adoption. This study contributes to the growing literature on scholarly communication by offering evidence from the HASS field, where limited studies have been conducted. Based on the findings, we recommend that academic librarians engage with faculty through outreach and workshops to change perceptions of OA and the institutional repository.
\end{abstract}

Keywords: Scholarly communication, open access, institutional repository, self-archiving, academic social networks

\section{Introduction}

The last decade has seen an increase in research on the open access (OA) movement. Open access refers to "the removal of restrictions associated with copyright and licensing, easy and quick access to research, lower cost to developing countries, faster publication of research, and wider research visibility" (Dulle et al., 2011); universities, funding agencies, policymakers and governments, have all developed and implemented policies to promote open access to research. OA journals are also increasing in availability and quality, while established publishers such as Elsevier, Springer, and Taylor \& Francis have started to provide OA options for many of their journals, albeit at a cost to authors.

\footnotetext{
*Corresponding author: Bhuva Narayan, University of Technology Sydney, Australia, E-mail: bhuva.narayan@uts.edu.au Edward J. Luca, University of Sydney, Australia

Belinda Tiffen, Ashley England, Mal Booth, Henry Boateng, University of Technology Sydney, Australia
} 
Alongside the OA movement, institutional repositories (IRs) have developed as "a digital archive of the intellectual product created by the faculty, research staff, and students of an institution" (Johnson, 2002). While these systems enable "green" open access, where a version of a work is self-archived or deposited in an OA repository, they have not achieved substantial adoption within academic circles. Some even suggest that IRs are at a dead end, and that green $\mathrm{OA}$ "must pivot towards alternatives that have viable paths forward: personal repositories, disciplinary repositories, social networks, and innovative combinations of all three” (Van de Velde, 2016).

Digital social media is also reshaping research practice and scholarly communication, as web technologies have made it even easier for scholars to share and disseminate their work (Veletsianos, 2016; Greenhow, Gleason, 2014). Many academics and researchers engage with social media and use it to promote their research outputs (Donelan, 2016; Manca, Ranieri, 2017). However, the literature on researchers' use and experience of social media in scholarly communication is inconsistent (Manca, Ranieri, 2017; Veletsianos, 2016). This calls for further research into the role of open access and digital social media in scholarly communication.

Academic librarians play a vital role in supporting researchers by informing them about developments and trends in scholarly communication (Rodriguez, 2014), including the provision of publications support, data management, and OA. Institutional repositories are typically developed and managed by the university library, meaning that academic librarians are often responsible for outreach and promotion of the repository to researchers at their institution. Despite these efforts, adoption of OA has been slow among researchers, especially those in the Humanities, Arts, and Social Sciences (HASS) (Suber, 2017). Policymakers, governments and universities are pushing to make open access standard, though many researchers still hold negative attitudes toward OA and OA journals (Rodriguez, 2014).

In this exploratory study, we investigated the level of awareness towards open access and adoption of institutional repositories amongst HASS researchers. We also examined the factors that influence researchers' choice of publishers and journal outlets, as well as their use of non-traditional channels for disseminating scholarly work. This study contributes to the growing literature on scholarly communication by offering evidence from the HASS field, which has limited evidence so far in regard to researchers' attitudes to OA and IR.

\section{Literature Review}

\subsection{Scholarly Communication}

Scholarly communication is defined as "the system through which research and other scholarly writings are created, evaluated for quality, disseminated to the scholarly community, and preserved for future use" (Association of College \& Research Libraries, 2003). Although this system of creation, organisation, and dissemination varies between disciplines, their outputs are "closely integrated into the promotion and tenure systems that reward academics" (Cullen, Chawner, 2011, p. 461). Tenure and promotion practices in many institutions appear to reinforce traditional scholarly models, resulting in many academics preferencing conventional, high-status journals that are looked upon favorably by committees (Odell et al., 2016). There exists a tension between "individual academics' dynamics in communicating research in new ways and the institutional constraints from old publishing paradigms" (Ren, 2015, p. 690).

Institutional repositories, which are typically set up and managed by university libraries, offer an avenue for the self-archiving of research outputs that is endorsed by the university and may even be supported by an institutional OA policy. Despite this, adoption of open access through self-archiving is often limited. Many researchers hold an unfavorable view of open access publishing and cite a range of issues including "author choice in the journal of publication, academic freedom, rights retention, and publisher relations" (Fruin, Sutton 2016, 477). Additionally, self-archiving in institutional repositories is often perceived as an administrative task, rather than a practice that increases the reach and impact of scholarly work. This stance suggests that academics do not clearly understand the benefits of making an open access version of their work freely available online (Kim, 2011; Marsh, 2015). 
Kim (2011) examines two main issues that affect academic adoption of IR: copyright concerns, and the time and effort needed to deposit one's outputs in the repository. Publisher policies are often challenging to interpret, which discourages academics from self-archiving for fear of violating their publisher agreements. Many academics are not aware of services such as SHERPA/RoMEO, which simplifies information about publisher self-archiving policies and license conditions for archiving various versions of a published article (Lwoga, Questier, 2015, p. 45). Additionally, academics are often already burdened by administrative tasks, termed "shadow work" (Butterwick, Dawson, 2005), that restrict their research and writing time, not to mention their increasingly tight teaching schedules. Such significant workloads result in an opportunity cost in the form of wasted time and resources within funded research (National Science Foundation, 2014). Without a clear understanding of the benefits of self-archiving one's own research outputs, academics are unlikely to adopt yet another system into their workload.

Bell, Foster and Gibbons (2005) argue that the issue of populating the repository with full-text materials is the most significant barrier to the success of an IR. A small or poorly designed repository is not an attractive place to deposit one's work, and without significant buy-in, repositories will remain a low priority. In Creaser et al.'s (2010) study, focus group participants considered the benefits of self-archiving to include "greater visibility, increased citation rates, and reputation building" (p.155); authors from the humanities and social sciences also considered citations very important compared to other disciplines.

Tenured professors are more likely to adopt experimental publishing and dissemination models than untenured professors, and are therefore more likely to use an institutional repository (Kim, 2011; SerranoVicente et al., 2016). Peekhaus and Proferes (2015) also found that while untenured faculty members attributed higher levels of importance to the free accessibility of research than their tenured colleagues, full professors were more likely to have published in an OA journal (Peekhaus, Proferes, 2015, p. 650).

According to Mercer (2011), librarians play a key role in the advocacy of scholarly communication practices such as open access. Stokker (2011) argues the same, and advises libraries and librarians to carve out a leadership role in the rapidly-changing environment of scholarly communications. Tomaszewski, Poulin and MacDonald (2013) propose that librarians proactively reach out to faculty within specific disciplines. Armstrong (2014) recommends that in order to effectively engage with faculty members, librarians need to help researchers by making IR more useful through providing statistics (on access, citations, and impact) to support tenure, and by improving discoverability through optimizing metadata for search engines.

Kennan (2008) notes that although the IR is not directly related to open access publishing except as a repository for papers via green $\mathrm{OA}$, it provides for the sharing of papers that are waiting in journal queues for publication, the backing up of scholarly works, and "the convenience of having all one's papers stored in one, easily accessible place, where they will be curated, stored and preserved” (Kennan, 2008, p. 204).

\subsection{Knowledge and Attitudes toward Open Access and Institutional Repositories}

A number of studies suggest that there is a significant gap between attitudes toward open access and actual practice. Despite acknowledging the need for changes to the current scholarly publishing model, in practice, the majority of faculty members still conform to traditional publishing practices (Peekhaus, Proferes, 2015).

Some sceptics also consider OA publishing as low quality, not peer-reviewed, or vanity publishing (Creaser et al., 2010, p. 152). In countries where OA is not common practice, academics tend to associate OA journals with "ephemeral publishing, poor archiving and low prospects for career advancement" (Peekhaus, Proferes, 2015, p. 643). Anecdotes in the media with stories of predatory publishing in the name of open access and of hoax papers being accepted at these outlets certainly confuse the issue. Singson, Thiyagarajan and Dkhar (2015) suggest that these negative perceptions and attitudes towards OA journals can be overcome through faculty outreach by librarians.

Lack of awareness of $\mathrm{OA}$ journals as alternatives to traditional outlets is also a significant hurdle. A study of researchers in Ghana showed that while the majority of respondents were aware of OA journals, their level of understanding varied considerably (Atiso et al., 2017). Respondents were largely aware of 
article processing charges (APCs) for gold OA, but fewer than half knew that they could use the Directory of Open Access Journals (DOAJ) to identify alternate publication outlets that do not charge APCs. Zhong and Jiang (2016) noted that a lack of government support and promotion has slowed the development of OA repositories in China, and that librarians themselves "have a long way to go to play a role in scholarly communication as the information and scholarship disseminator" (Zhong, Jiang, 2016, p. 743).

Rodriguez's (2014) study explored faculty members' awareness of OA publishing and focused on how factors such as age, seniority, or rank affected their attitudes. While their results pointed to a growing trend in self-reported awareness of OA across all demographic groups, they identified a need for further research to explore "discipline specific concerns and OA publishing activity related to the tenure process" (Rodriguez, 2014, p. 609). There is evidence to show that awareness of open access and institutional repositories differs depending on subject area (Serrano-Vicente et al., 2016). For example, "uncertainty around OA publication of monographs as well as lack of funding to support pre-publication APCs" has led to some hostility towards OA in the humanities (Pinfield, 2015).

In Bongiovani et al.'s (2014) study, many respondents supported open access to research, but few actually used institutional repositories to disseminate their research. Those who did were motivated by altruism, as well as providing easier access for colleagues, students and the general public. Similar findings were also reported in Serrano-Vicente, Melero and Abadal's study (2016).

Kim's (2007) conceptual framework of factors influencing faculty contribution to IRs describes four categories: costs, extrinsic and intrinsic benefits, contextual factors, and individual traits. Extrinsic benefits include accessibility through a permanent URL, wider dissemination, and increased likelihood of citation, academic acknowledgment and professional recognition. Altruism is an intrinsic benefit realised through sharing research publications with others. A further study showed that IR contributors viewed digital preservation as the primary reason, or incentive, for contributing to IRs (Kim 2011). Conversely, IR non-contributors were suspicious of the long-term preservation afforded by the IR due to a perception of insufficient human and financial resources in university libraries.

Xia (2007) conducted a survey to determine whether self-archiving was more likely in some subject areas compared to others. Despite an existing culture of depositing in subject repositories in physics and economics, increased engagement with the repository was instead attributed to the existence of a mediated deposit process and an institutional mandate. OA policies, either at an institutional or funding body level, have made significant contributions to the uptake of open access and have increased in numbers in recent years (Pinfield 2015).

Narayan and Luca conducted studies investigating the usability of the institutional repository (Luca, Narayan, 2016), and also the barriers faced by researchers in adopting open access practices (Narayan, Luca, 2017). They describe the redesign of an institutional repository which resulted in improved user experience by implementing a new visual design, reorganizing the navigational system and using less jargon in the user interface to make the system more accessible to a wider audience. Their findings suggest that academics deposit their research outputs "for the purpose of their own accounting to faculty, and not to increase the visibility of their research through open access" (Luca, Narayan, 2016, p. 280).

Institutional repositories could play a more significant role in removing the many barriers to research outputs in the future, but appear to be constrained by a lack of wide adoption, limited integration into promotion and reward systems at an institutional level, and accessibility and usability issues.

\subsection{The role of social media technologies in promoting research outputs}

Web technologies have fundamentally altered the nature of scholarly communication, and provide essential infrastructure to support OA practices. Digital social media in particular, has transformed the professional identity of academic staff and researchers by enabling digital and networked scholarship practices (Greenhow, Gleason, 2014; Veletsianos, 2016; Weller, 2011).

Twitter, LinkedIn, Academia.edu, Facebook, ResearchGate, YouTube, blogs and other platforms are common tools for promoting and disseminating academic work. These platforms allow researchers 
to make connections, promote their work, build networks, access support from fellow researchers, and encourage a culture of openness and sharing (Gruzd, Goertzen, 2013). Nentwich and König (2014) found that platforms such as Facebook increase opportunities for informal academic communication by both academic organisations and individual scholars.

Al-Aufi and Fulton (2015) found a lack of institutional encouragement or incentives was seen as the most challenging barrier to researchers' use of informal scholarly communication channels. Stewart argues that networked scholarship "fosters a techno-cultural scholarly system structured primarily around individual connections" (Al-Aufi, Fulton, 2015, p. 327), creating a system which is distinct and separate to the traditional institutional model of scholarship. Sugimoto et al.'s (2017) review found a diverse body of work providing evidence of the popularity and interest in social media for academic purposes, noting such interest is matched by funding bodies and researchers demand for "indicators that reflect academic productivity and influence beyond papers published and citations received” (p. 2051). Veletsianos (2016) notes that evidence to describe researchers' experiences in using social media is still fragmented and not well understood. Tenopir et al.'s (2016) study found that such forms of informal communication were not considered trustworthy by researchers. The majority of respondents in their study also did not see selfarchiving as a reliable way to reach a broader audience, nor was blogging considered a good way to test ideas (Tenopir et al., 2016, p. 2355).

Alongside traditional social media channels, tools for the specific purpose of academic networking and communication have become part of the research landscape. Popular examples include ResearchGate, Academia.edu and Mendeley. These platforms often allow a form of self-archiving, though they lack the copyright checks and long-term archiving offered by institutional repositories. While these services "have the potential to increase readership and citation counts of research outputs... their legitimacy remains a contentious issue" (Narayan, Luca, 2017). Many are operated by commercial entities that profit from the scholarship of well-intentioned researchers who are simply trying to make their work accessible to a wider audience (Bond, 2017).

Donelan (2016) conducted research into the motivations for social media use in scholarly communication, which included self-development, and maintaining and expanding networks. Donelan found that "with increasing levels of activity, the number of motivations for using social media increase, as does the perceived number of successful outcomes, including contributions towards career progression" (2016, p. 706).

Niyazov et al.'s (2016) study highlights the role that academic social networks can play in increasing citation count. They found that papers available on Academia.edu and published in a median impact factor journal received, on average, a 69\% boost in citations over five years compared to those that weren't available online. These papers also received " $58 \%$ more citations than articles only posted to other online venues, such as personal and departmental home pages” (Niyazov et al., 2016, p.1). Consequently, open access to research not only helps researchers, but also helps in improving the impact factors of the journals the papers come from.

Goodfellow (2013) conceptualizes three dimensions of academic practice, scholarship, digitality and openness, as, an "impossible triangle" (Goodfellow, 2013, p. 3), and advocates for further consideration of the tension between these practices. Like awareness and adoption of OA, disciplinary differences are a significant factor in influencing social media usage for scholarly purposes (Manca, Ranieri, 2016). Jamali, Nicholas and Herman report that "life scientists used ResearchGate the most and those from the arts and humanities the least" (Jamali et al., 2016). They also note that younger scholars look to benefit most from these emerging reputational platforms, as they are likely to have a broader notion of "reputation" than their older peers and to include social media metrics in grants and promotion applications (Jamali et al., 2016). Elsayed (2016) reported that scholars in scientific disciplines displayed higher usage rates of social media compared to other subject areas. Ortega (2015) found that while Academia.edu was extremely popular in the humanities and social sciences, biologists typically preferred ResearchGate. Manca and Ranieri (2017) found gender and seniority to have limited impact on researchers' motivations in their study of the use of social networks for scholarly communication. 


\section{Methodology}

This study used a survey research design through an online questionnaire active between October-December 2017. The questionnaire was divided into seven sections and asked questions about:

- Demographic data, including school, appointment level, publishing experience and output type of the respondents

- Factors considered when selecting a publisher or journal

- Post-publication activities

- Tools used to measure the impact of their research output

- Actions taken to promote their research

- Kinds of scholarly communication training needed in the future

- How often various sources of scholarly literature were used

The questionnaire was administered via a faculty listserv that included all academics and researchers within the HASS faculty (121 research-active academics, of which 102 were full-time staff and 19 part-time), but only 49 responded. This represents a $40.5 \%$ response rate. The study captured the following demographic data of the respondents; school, level of appointment, experience in publishing, and type of research output. With regard to type of research output, the study sought to ascertain whether the respondents' research outputs were presented in traditional outlets such as scholarly books or monographs, chapters in scholarly books, scholarly articles in refereed journals, and refereed conference papers, or non-traditional research outputs (NTROs) such as websites, commissioned reports, visual arts, film, and dance.

Out of the 49 respondents, $24.5 \%$ were responses from academics at the professorial level; $22.4 \%$ were Senior Lecturers, 18.4\% Associate Professors, 4.1\% Scholarly Teaching Fellows, 4.1\% Casuals, 2\% Research Assistants and 2\% were Visiting Academics. The majority (61.22\%) of the respondents had 11 years or more of publishing experience; $18.4 \%$ had 6-10 years of publishing experience; $14.3 \%$ had $1-2$ years of publishing experience and the remainder (6.1\%) had 3-5 years of publishing experience. From these results, it can be inferred that the respondents had a good knowledge of scholarly communication. Additionally, the majority (83.7\%) of the respondents published in traditional research formats (e.g. journal articles, books, book chapters), with only $16.3 \%$ producing NTROs.

\section{Findings}

\subsection{Factors that influence respondents' choice of a publisher or a journal}

Respondents were asked to indicate the extent to which each of the below factors (shown in Figure 1) influenced their decisions when choosing a journal or a publisher for their research outputs. The reputation of the outlet was the most critical factor that influences the choice of a journal or a publisher; $26.2 \%$ indicated that reputation was extremely influential while $20.7 \%$ indicated that it was very influential. $27.2 \%$ of respondents said that the listing status of a journal in an indexing service does not influence their choice of publishers at all. Similarly, 22.8\% said that journals listed in the 2010 Excellence in Research Australia (ERA) journal rankings list did not influence them at all.

Reputation is a very influential factor when it comes to the choice of a journal or publisher among our respondents (Figure 2). On average, personal experience with the publisher, colleague recommendations, and journal impact factor somewhat influenced the respondents' choice of a journal or a publisher, with a mean average of nearly 3 for each of these factors. 


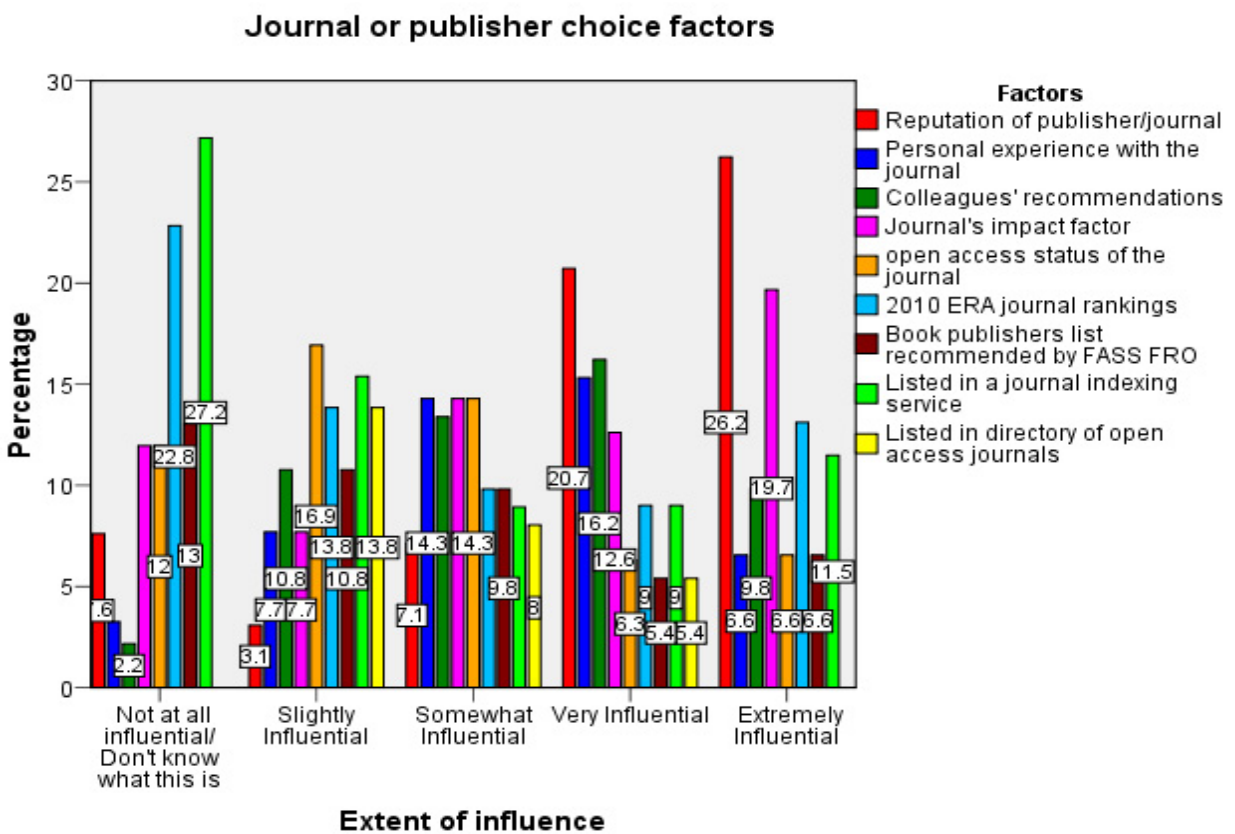

Figure 1: Factors influencing the choice of a journal or publisher

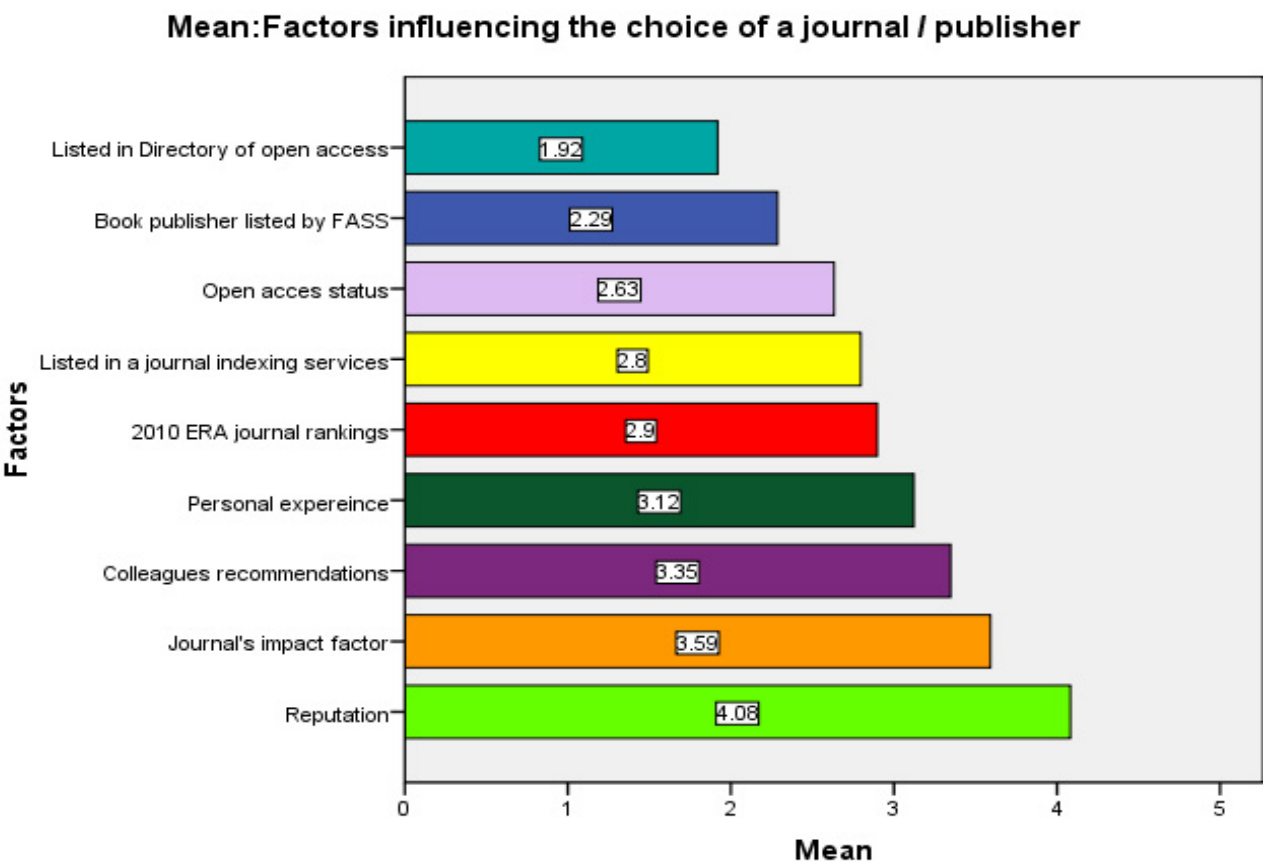

Figure 2: Mean of the factors influencing the choice of a journal or a publisher 


\section{Knowledge of Open Access}

We also wanted to identify our respondents' self-reported level of awareness of open access (extremely aware, moderately aware, not at all aware, slightly aware, somewhat aware). Figures 3 and 4 present the different types of open access and respondents' level of awareness.

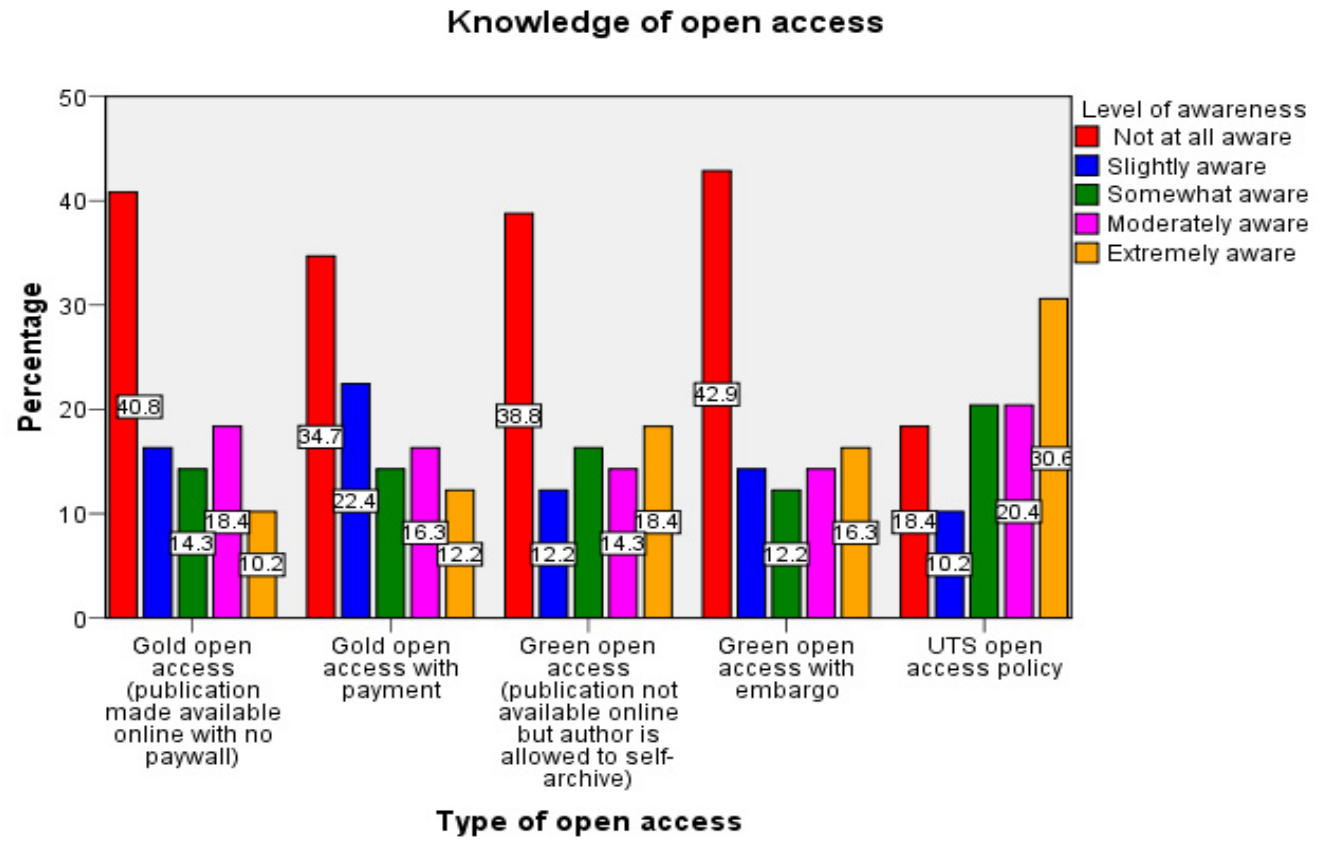

Figure 3: Level of awareness of Open Access

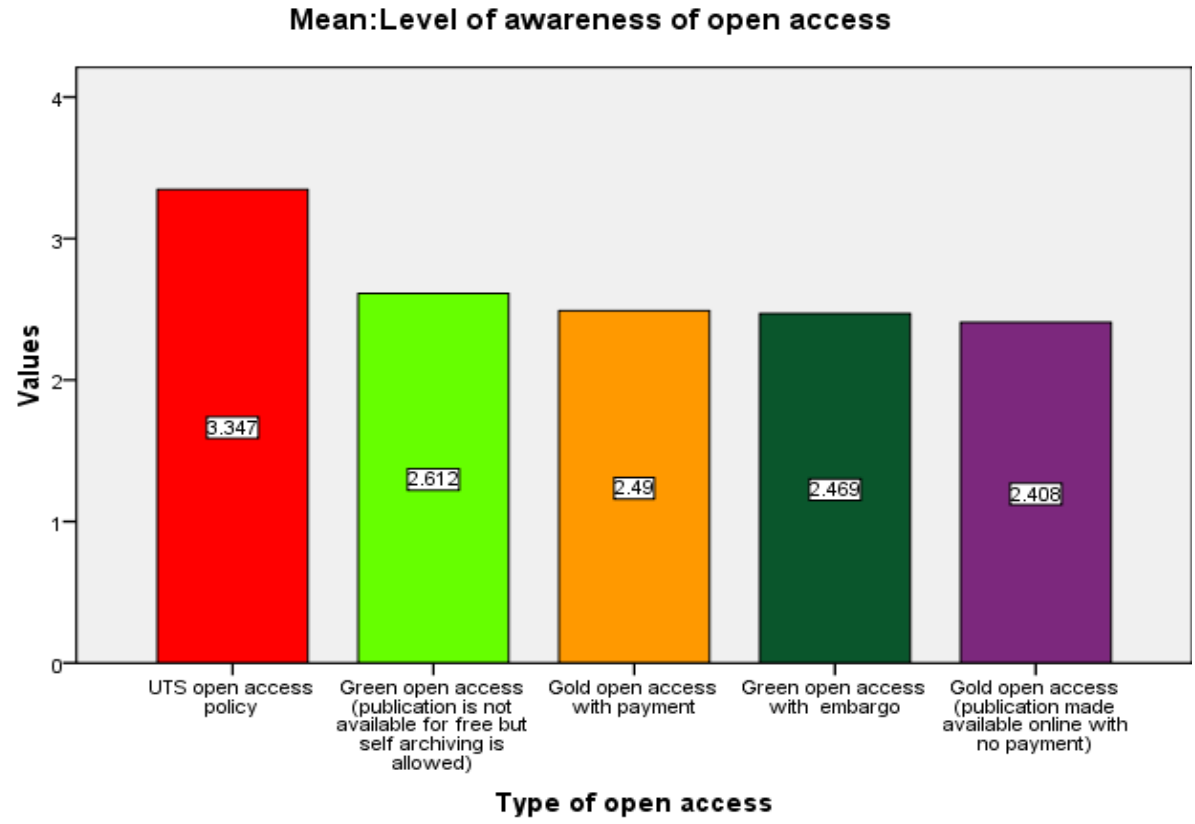

Figure 4: Average level of awareness of Open Access 
Many (30.6\%) respondents indicated that they are extremely aware of the UTS Open Access Policy that mandates the deposit of both published and pre-print versions of research outputs in UTS's institutional repository. Another $20.4 \%$ are moderately aware of this same policy. Our results also show that many of the respondents are not aware of; Green Open access with embargo (42.9\%), Gold open Access where a publication is made available online with no paywall (40.8\%), Green open access (publication not available for online but author is allowed to self-archive) (38.8\%), Gold open access with payment (34.7\%), and the UTS Open Access Policy (18.4\%). These results suggest that many of the respondents have somewhat limited knowledge of $\mathrm{OA}$, which can affect their awareness and actual adoption of OA journals.

On average, the respondents were more aware of the UTS Open Access Policy than the various forms of Open Access we measured (Figure 4). This is not all that surprising to us, since knowledge of this policy is a requirement for academics at the university.

\section{Promoting publication success with social media}

Given the integral role of social media in contemporary scholarly communication, we examined which social media platforms are most used to promote research publications and how often they are used (never, rarely, occasionally, sometimes, frequently, usually, every time).

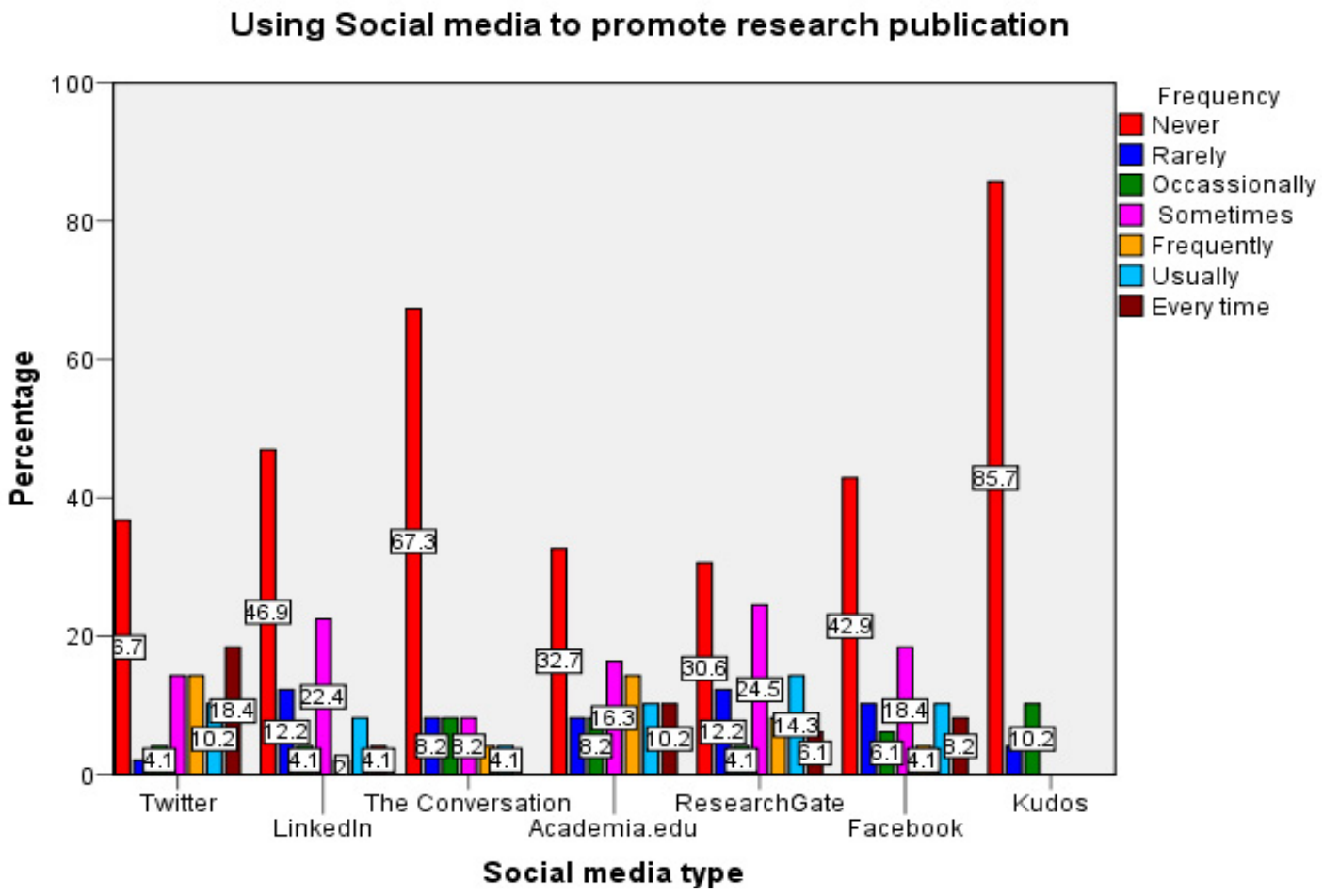

Figure 5: Promoting publication success with social media

The findings are presented in Figure 5. Our results showed that 18.4\% of respondents use Twitter every time to promote their research outputs, and Academia.edu (10.2\%), Facebook (8.2\%), and ResearchGate (6.1\%) are also used every time. Furthermore, most (85.7\%) respondents never use Kudos to promote the success of their research outputs. The results suggest that Twitter is the most popular social media tool used by respondents to promote their research publications. 


\section{Measuring Research Output Performance}

Various tools and metrics were used to assess the impact of research outputs. In this study we found that among all the metrics, Google citation was the most (25.8\%) used metric to assess the impact of research outputs. This was followed by h-index (20.2\%), downloads from Academia.edu and ResearchGate (13.5\%), i10-index (10.1\%), other metrics (10.1\%), Scopus (6.7\%), Almetrics (6.7\%), Web of Science (3.4\%), Kudos $(2.2 \%)$, and ImpactStory (1.1\%). Figure 6 provides a summary of these results.

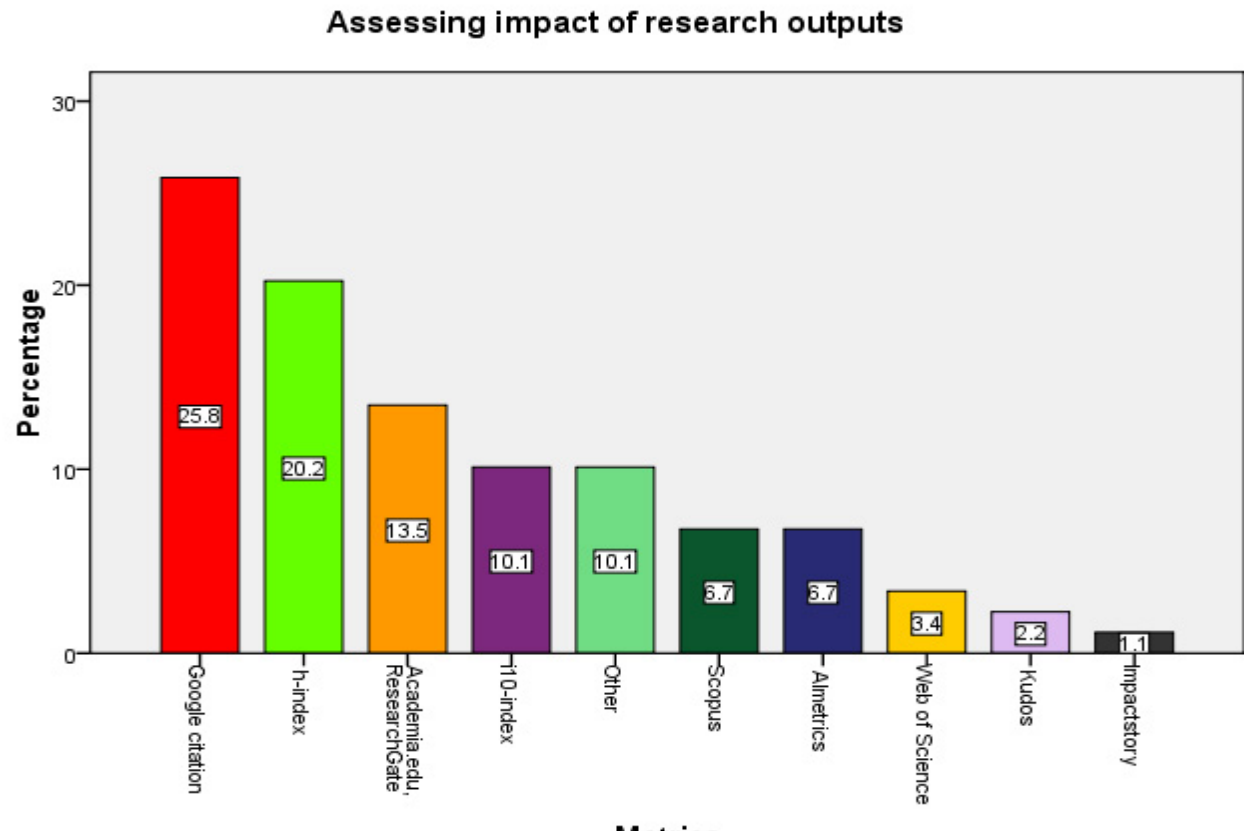

Metrics

Figure 6: Metrics for measuring impact of research outputs

Our results indicated that Google Scholar metrics (Google citations, h-index, and i-10 index) were the most popular research impact measurement tools among the respondents. Download counts from Academia. edu, and ResearchGate were also important measures of research impact for the participants.

\section{Discussion and Implications}

Our findings show that the reputation of the publisher or journal and the journal's impact factor are extremely influential in researchers' choice of journal or publisher. The reputation of journals and publishers still plays a key role in recruitments and promotions in academic institutions (Odell et al. 2016), and this is reflected in the way many of our respondents make decisions about scholarly publishing.

Our findings paralleled those from Jamali et al. (2016), who noted that many researchers, especially young scholars, are now more concerned than ever with their reputation. This also explains why many researchers employ social media to promote their research outputs, make them accessible online and consequently increase their citations (Narayan, Luca, 2017; Niyazov et al., 2016). Even though our respondents were concerned with the reputation of the journal where they published, they hardly engaged in activities that likely increase a journal's impact factor and reputation through their own citation practices or by promoting their own publications and making them more accessible. This shows that researchers do not always understand how a journal achieves its impact factor, and how their own actions and decisions 
can contribute to the impact factor of a journal. Hence, there appears to be a disconnect between the reputation that researchers strive to achieve, and the efforts that they put in to maximize the reach of their own work. We also note that the use of social media in promoting research outputs has not been all that significant nor do researchers systematically employ these tools as part of their research promotion.

Unlike findings from Elsayed (2016) and Ortega (2015), only a few of the researchers in our study used Academia.edu or ResearchGate. We also noticed that, generally, many of the respondents demonstrated limited knowledge of OA journals. They were more aware of their own institution's Open Access Policy (mainly related to depositing a copy in the institutional repository) than policies mandated by publishers and funding bodies. For those who do deposit their research outputs in the university's IR, it raises the question of whether they are doing so as an act of compliance, or whether they are doing so to increase the accessibility of their work; the university's records show approximately $30 \%$ compliance with this deposit policy (Narayan, Luca, 2017), which is somewhat higher than other universities in Australia, although we note this figure is for the whole university rather than just the HASS faculty we studied. In either case, it is possible that these researchers will realize the value of the institutional repository when it helps others find and cite their work more easily, and that over time, they will also realize the value of open access publishing through mandates from grant organisations that require it.

\section{Conclusion}

This was an exploratory study to understand the current state of awareness and use of open access and institutional repositories within a HASS faculty. It also sought to assess researchers' level of awareness of open access, and the channels used to communicate research outputs. Although a journal's impact factor is extremely influential in researchers' choice of journals to publish in, our findings show that researchers make little effort to contribute to increasing a journal's impact factor. Our findings also suggest that the use of social media in scholarly communication within HASS is still at the embryonic stage, and its potential in increasing the visibility of research is yet to be fully realised by researchers. Finally, our research suggests that institutional policies on OA do have the potential for improving researchers' attitudes towards and adoption of open access. Given that university libraries are often responsible for managing the institutional repository, this study informs library practice by highlighting the need for librarians to educate researchers about open access, institutional repositories, and scholarly communication in general.

\section{Limitations and Recommendations for future research}

This study contributes to the growing literature on OA and IR; however, there are some limitations. Thus, care must be taken in applying the findings of this study. Firstly, the study relied on respondents from one faculty within one university, which limits the scope of the study, and consequently the application of the findings. Similarly, there was a low (40.5\%) response rate. In the future, we aim to expand the scope of the study to cover all discipline areas, and also to other universities in Australia so the findings may have a wider application.

Secondly, we recommend that future studies should consider a comparative study of scholarly communication practices of researchers in developing economies and those in developed economies, especially as open access is key to the accessibility of research in developing countries. Lastly, we recommend that future studies should investigate how university libraries can collaborate with researchers to develop services that can promote OA.

Acknowledgements: This study was made possible by a LISRA-RADAR award as part of an Australian Research Council grant and we acknowledge the generous support of Prof. Helen Partridge and Prof. Lisa Given in supporting this study. 


\section{References}

Association of College \& Research Libraries (2003). Principles and Strategies for the Reform of Scholarly Communication 1. Retrieved from http://www.ala.org/acrl/publications/whitepapers/principlesstrategies (Archived by WebCite ${ }^{\circledR}$ at http:// www.webcitation.org/6nr5uq4V3)

Al-Aufi, A., Fulton, C. (2015). Impact of social networking tools on scholarly communication: A cross-institutional study. The Electronic Library, 33(2), 224-241.

Armstrong, M. (2014). Institutional repository management models that support faculty research dissemination. OCLC Systems \& Services, 30(1), 43-51.

Atiso, K., Adkins, D., Borteye Mensah, E. (2017). Knowledge of Open Access Journals Among Research Scientists in Ghana. The Serials Librarian, 73(3-4), 327-337.

Bell, S., Fried Foster, N., Gibbons, S. (2005). Reference librarians and the success of institutional repositories. Reference Services Review, 33(3), 283-290.

Bongiovani, P. C., Guarnieri, G., Babini, D., Lopez, F. A. (2014). Acceso abierto en la Universidad Nacional de Rosario necesidades y practicas de los docentes/ investigadores. Informacion, Cultura y Sociedad, 30, 13-34.

Butterwick, S., Dawson, J. (2005,). Undone business: Examining the production of academic labour. Women's Studies International Forum, 28(1), 51-65.

Creaser, C., Fry, J., Greenwood, H., Oppenheim, C., Probets, S., Spezi, V., White, S. (2010). Authors' awareness and attitudes toward open access repositories. New Review of Academic Librarianship, 16(S1), 145-161.

Crow, R. (2002). The Case for Institutional Repositories: A SPARC Position Paper. Association of Research Libraries, no. 223 (August 2002): 1-4. http://www.sparc.arl.org/resources/papers-guides/the-case-for-institutional-repositories (Archived by WebCite ${ }^{\circ}$ at http://www.webcitation.org/6xGcL6307)

Cullen, R., Chawner, B. (2011). Institutional repositories, open access, and scholarly communication: a study of conflicting paradigms. The Journal of Academic Librarianship, 37(6), 460-470.

Donelan, H. (2016). Social media for professional development and networking opportunities in academia. Journal of Further and Higher Education, 40(5), 706-729.

Dulle, F. W., M. K. Minishi-Majanja, L. M. Cloete, (2011). The Adoption of Open Access Scholarly Communication in Tanzanian Public Universities: Some Influencing Factors. Mousaion 29(1), 112-135.

Elsayed, A. M. (2016). The use of academic social networks among Arab researchers: A survey. Social Science Computer Review, 34(3), 378-391.

Fruin, C., Sutton, S. (2016). Strategies for success: open access policies at North American educational institutions. College \& Research Libraries, 77(4), 469-499.

Goodfellow, R. (2013). Scholarly, digital, open: an impossible triangle?. Research in Learning Technology, 21, 1-15.

Greenhow, C., Gleason, B. (2014). Social scholarship: Reconsidering scholarly practices in the age of social media. British Journal of Educational Technology, 45(3), 392-402.

Gruzd, A., Goertzen, M. (2013). Wired academia: Why social science scholars are using social media. In: Proceedings of the 46th Hawaii International Conference on System Sciences (HICSS) (pp. 3332-3341). Piscataway, NJ: IEEE.

Jain, P., Bentley, G. Oladiran, M.T. (2009). The role of institutional repository in digital scholarly communications". In: African Digital Scholarship and Curation Conference (pp. 12-14).

Jamali, H. R., Nicholas, D., Herman, E. (2016). Scholarly reputation in the digital age and the role of emerging platforms and mechanisms. Research Evaluation, 25(1), 37-49.

Johnson, R. (2002). Institutional repositories: partnering with faculty to enhance scholarly communication. D-Lib Magazine, 8(11), http://www.dlib.org/dlib/november02/johnson/11johnson.html

Kennan, M. A. (2008). Reassembling scholarly publishing: open access, institutional repositories and the process of change (PhD thesis). Sydney: The University of New South Wales. Retrieved from http://handle.unsw.edu.au/1959.4/10148

Kim, J. (2007). Motivating and impeding factors affecting faculty contribution to institutional repositories. Journal of Digital Information, 8(2), https://journals.tel.org/ jodi/index.php/ jodi/article/ view/193/177

Kim, J. (2011). Motivations of faculty self-archiving in institutional repositories. The Journal of Academic Librarianship, 37(3), 246-254.

Luca, E., Narayan, B. (2016). Redesigning the open-access institutional repository: A user experience approach. In A. Morishima, A. Rauber, \& C. li Liew (Eds.), Lecture Notes in Computer Science (pp. 275-281). Berlin: Springer Verlag.

Lwoga, E. T., Questier, F. (2015). Open access behaviours and perceptions of health sciences faculty and roles of information professionals. Health Information \& Libraries Journal, 32(1), 37-49.

Manca, S., Ranieri, M. (2017). Exploring Digital Scholarship. A Study on Use of Social Media for Scholarly Communication among Italian Academics. In Esposito A. (Ed.), Research 2.0 and the Impact of Digital Technologies on Scholarly Inquiry (pp. 116-141). Hershey, PA: IGI Global.

Marsh, R. M. (2015). The role of institutional repositories in developing the communication of scholarly research. OCLC Systems \& Services: International digital library perspectives, 31(4), 163-195. 
Mercer, H. (2011). Almost halfway there: An analysis of the open access behaviors of academic librarians. College \& Research Libraries, 72(5), 443-453.

Narayan, B., Luca, E. (2017). Issues and challenges in researchers' adoption of open access and institutional repositories: a contextual study of an institutional repository. Information Research: An International Electronic Journal, 22(4). Retrieved from http://www.informationr.net/ir/22-4/rails/rails1608.html

National Science Foundation (2014). Reducing investigators' administrative workload for federally funded research. Report by the National Science Board. Arlington, VA: National Science Foundation.

Nentwich, M., König, R. (2014). Academia goes Facebook? The potential of social network sites in the scholarly realm. In Opening science (pp. 107-124). Springer International Publishing. Niyazov, Y., Vogel, C., Price, R., Lund, B., Judd, D., Akil, A., Mortonson, M., Schwartzman, J., Shron, M. (2016). Open access meets discoverability: Citations to articles posted to Academia.edu. PloS one, 11(2), 1-23.

Odell, J., Coates, H., Palmer, K. (2016). Rewarding open access scholarship in promotion and tenure: Driving institutional change. College \& Research Libraries News, 77(7), 322-325.

Ortega, J. L. (2015). Disciplinary differences in the use of academic social networking sites. Online Information Review, 39(4), 520-536.

Peekhaus, W., Proferes, N. (2015). How library and information science faculty perceive and engage with open access. Journal of Information Science, 41(5), 640-661.

Ren, X. (2015). The quandary between communication and certification: Individual academics' views on Open Access and open scholarship. Online Information Review, 39(5), 682-697.

Rodriguez, J. E. (2014). Awareness and attitudes about open access publishing: A glance at generational differences. The Journal of Academic Librarianship, 40(6), 604-610.

Serrano-Vicente, R., Melero, R., Abadal, E. (2016). Open Access Awareness and Perceptions in an Institutional Landscape. The Journal of Academic Librarianship, 42(5), 595-603.

Singson, M., Joy, M. G., Thiyagarajan, S., Dkhar, V. (2015). Perceptions of open access publishing by Faculty at Pondicherry University: A survey. International Information \& Library Review, 47(1-2), 1-10.

Stewart, B. E. (2015). In abundance: Networked participatory practices as scholarship. International Review of Research in Open and Distributed Learning, 16(3), 318-340.

Stokker, J. (2011). Open access: a widening agenda - an Australian perspective. Paper presented at the IATUL 2011 Conference, Warsaw, Poland. Retrieved from http://docs.lib.purdue.edu/iatul/2011/papers/14/ (Archived by WebCite ${ }^{\circledR}$ at http:// www.webcitation.org/6xGdDJzwH)

Suber, P. (2017). Why Is Open Access Moving So Slowly In The Humanities? Retrieved September 27, 2017, from https://blog. apaonline.org/2017/06/08/open-access-in-the-humanities-part-2/ (Archived by WebCite ${ }^{\circledR}$ at http://www.webcitation. org/6xGcXh34v)

Sugimoto, C. R., Work, S., Larivière, V., Haustein, S. (2017). Scholarly use of social media and altmetrics: A review of the literature. Journal of the Association for Information Science and Technology, 68(9), 2037-2062.

Tenopir, C., Levine, K., Allard, S., Christian, L., Volentine, R., Boehm, R., Nichols, F., Nicholas, D., Jamali, H. R., Herman, E., Watkinson. A. (2016). Trustworthiness and Authority of Scholarly Information in a Digital Age: Results of an International Questionnaire. Journal of the Association for Information Science and Technology, 67(10), 2344-2361.

Tomaszewski, R., Poulin, S., MacDonald, K. I. (2013). Publishing in discipline-specific open access journals: opportunities and outreach for librarians. The Journal of Academic Librarianship, 39(1), 61-66.

University of Technology Sydney (UTS). (2013). Open Access Policy. Retrieved 21 January, 2017, from: http://www.gsu.uts.edu. au/policies/open-access.html (Archived by WebCite ${ }^{\circledR}$ at http://www.webcitation.org/6xGcr9Ns0)

Veletsianos, G. (2016). Social media in academia: Networked scholars. New York, NY: Routledge.

Van de Velde, E. (2016). Let IR RIP. Retrieved 30 January, 2017, from: http://scitechsociety.blogspot.com.au/2016/07/let-ir-rip. html (Archived by WebCite $®$ at http://www.webcitation.org/6xGd3de8X)

Xia, J. (2007). Assessment of self-archiving in institutional repositories: Across disciplines. The Journal of Academic Librarianship, 33(6), 647-654.

Zhong, J., Jiang, S. (2016). Institutional repositories in Chinese open access development: Status, progress, and challenges. The Journal of Academic Librarianship, 42(6), 739-744. 